\title{
ENDOGENOUS MARKUPS AND FISCAL POLICY
}

\author{
Luís F. Costa
}

\begin{abstract}
This note analyses a simple imperfectly competitive general equilibrium model where the entry mechanism generates an endogenous markup. In this second-best world fiscal policy is more effective than in Walrasian or in fixed-markup monopolistic competition models, as it produces efficiency gains through entry.
\end{abstract}

JEL Classification: E62, L13, L16

Keywords: Endogenous markups; Entry; Multiplier; Fiscal Policy

Luís F. Costa

Instituto Superior de Economia e Gestão

Universidade Técnica de Lisboa

Rua do Quelhas 6

1200-781 LISBOA

Portugal

Tel.: +351-213925976

Fax: +351-213922808

E-mail: lukosta@iseg.utl.pt

http://www.iseg.utl.pt/ lukosta/

This version: 11 November 2002

This version is preliminary and incomplete. Please, do not quote without permission. 



\title{
ENDOGENOUS MARKUPS AND FISCAL POLICY*
}

\author{
By Luís F. Costa
}

This article analyses a simple imperfectly competitive general equilibrium model where the entry mechanism generates an endogenous markup. In this second-best world fiscal policy is more effective than in Walrasian or in fixedmarkup monopolistic competition models, as it produces efficiency gains through entry.

\section{Introduction}

The role of imperfect competition in the transmission mechanism of fiscal policy has been analysed by several authors following the seminal paper by Hart (1982). Dixon (1987) and Mankiw (1988) demonstrated the multiplier is strictly increasing in the monopoly degree, as pure profits are generated, stimulating households' income and consequently aggregate demand. Startz (1989) introduced entry in a 'long-run' model, eliminating pure profits and, as a consequence, switching the profit-multiplier mechanism off. Dixon and Lawler (1996) showed Startz's conclusions strongly depended on the class of functionals chosen, namely constant marginal shares in the utility function. Recent developments extended the basic Dixon, Mankiw and Startz

\footnotetext{
${ }^{*}$ I wish to thank Paulo Brito, Huw Dixon, Teresa Lloyd Braga, and the participants at a seminar at the Portuguese Catholic University for their useful comments and suggestions. The usual disclaimer applies.
} 
(DMS) framework: e.g., Heijdra and van der Ploeg (1996), Molana and Montagna (2000), Reinhorn (1998), and Torregrosa (1998).

However, all these models share a common Bertrandian flavour: they use Dixit and Stiglitz (1977) monopolistic competition as the basic market structure ${ }^{1}$. Given the CES sub-utility function assumed, each firm faces a constant-elasticity demand function, hence the markup is also constant. This assumption is not consistent with the evidence presented in Galí (1995), Martins and Scarpetta (1999), and Rotemberg and Woodford (1995) that support the hypothesis of counter-cyclical markups.

Rotemberg and Woodford (1995), Rotemberg and Woodford (1991) and Galí (1994a) Galí (1994b) Galí (1995), inter alia, produced dynamic general equilibrium models with endogenous markups. However, they were not especially concerned with fiscal policy effectiveness. Wu and Zhang (2000) assumed monopolistic producers are large at the economy level therefore considering the feedback effects of their own prices on aggregate price and quantity indices. However, the endogenous markup disappears for a large number of goods in the economy.

In this paper I use a Cournotian Monopolistic Competition framework, following d'Aspremont et al. (1997), generating an endogenous markup when entry means more firms per industry. Here, fiscal policy produces an aggregate demand externality as it stimulates entry, pushing the markup downwards, and introducing efficiency gains in the economy.

\footnotetext{
${ }^{1}$ Dixon (1987) and Hart (1982) are exceptions where the flavour is mainly Cournotian, but entry is not considered.
} 
2. The model

I use the basic structure of the DMS framework, and Mankiw's notation wherever possible. This is a closed economy populated by a large number of identical households, consuming $n$ (a large number of) imperfect substitutes and supplying labour, which is the only input.

\subsection{The representative household}

Households maximise a Cobb-Douglas utility function given by $U=C^{\alpha} \cdot(1-L)^{1-\alpha}$, where $C$ is a CES consumption basket, $L$ represents labour supply for a unit time endowment, and $0<\alpha<1$. For sake of simplicity, I assume there is no love for variety in consumption, hence the sub-utility function is given by

$$
C=n^{\frac{1}{1-\sigma}} \cdot\left[\sum_{j=1}^{n}\left(c_{j}\right)^{\frac{\sigma-1}{\sigma}}\right]^{\frac{\sigma}{\sigma-1}}
$$

where $c_{j}$ stands for households' consumption of variety $j=1, \ldots, n$, and $\sigma>1$ is the elasticity of substitution ${ }^{2}$. The aggregate consumption good $C$ is chosen to be the numéraire, so $P$, the appropriate cost-of-living index, is normalised to unity ${ }^{3}$. The budget constraint is given by

${ }^{2}$ A weaker condition than $\sigma>1$ would be sufficient to ensure the existence of a unique equilibrium in this model.

${ }^{3}$ This price index is given by $P=\left[\frac{1}{n} \cdot \sum_{j=1}^{n}\left(p_{j}\right)^{1-\sigma}\right]^{\frac{1}{1-\sigma}}$, where $p_{j}$ stands for the price of good $j$. 


$$
\sum_{j=1}^{n} p_{j} \cdot c_{j}=w \cdot L+\Pi-T
$$

where $w$ represents the wage rate, $\Pi$ stands for profit income, and $T$ is a lump-sum tax. The optimisation problem is solved in the usual two-stage procedure: (i) the demand for aggregate consumption and the labour supply are derived, maximising utility given the duality condition $\sum_{j=1}^{n} p_{j} \cdot c_{j}=P . C$ :

$$
\begin{aligned}
& C=\alpha \cdot(w \cdot 1+\Pi-T), \\
& L=\alpha .1-(1-\alpha) \cdot \frac{\Pi-T}{w},
\end{aligned}
$$

(ii) demand functions for each good are derived, minimising expenditure in it

$$
c_{j}=\left(p_{j}\right)^{-\sigma} \cdot \frac{C}{n} .
$$

\subsection{The government}

I assume government has the same preferences for varieties as the households, its expenditure, $G$, is pure waste, and it is financed by the above-mentioned lump-sum tax levied on households.

\subsection{Firms}

The production sector is composed by $n$ identical industries, each one producing a differentiated good. The number of industries is assumed to be large enough to rule out feedback effects from the macroeconomic level. Thus, macroeconomic variables are taken as given by firms. Each industry is composed by $m \geq 1$ identical producers. I assume firms compete over quantities with other firms in the same industry (intra- 
industrial Cournot competition), and they compete over prices with firms in other industries (inter-industrial Bertrand competition). This set of conjectures corresponds to Cournotian Monopolistic Competition (CMC) and it nests Monopolistic Competition (MC) as a special case where $m=1$. Firms are labelled such that industry $j=1, \ldots, n$ is composed by producers from $(j-1) . m+1$ to $j . m$.

Production technologies are identical in all industries and they are given by $y_{i}+\Phi=1 . L_{i}$, where $y_{i} \geq 0$ represents the output of firm $i, \Phi \geq 0$ is a fixed cost, and $L_{i}$ its labour input. The representative firm maximises its profits given by $\pi_{i}=p_{j} \cdot y_{i}-w \cdot L_{i}$, subject to the (i) production function; (ii) the 'objective' market demand function given by $Y_{j}=\left(p_{j}\right)^{-\sigma} . Y / n$, where $Y_{j}$ represents demand for variety $j$, and $Y=C+G$ stands for aggregate demand; and (iii) the market-clearing condition given by $Y_{j}=\sum_{i=(j-1) \cdot m+1}^{j . m} y_{i}$. In an intra-industry symmetric equilibrium the condition equalising marginal revenue to marginal cost is given by

$$
p_{j} \cdot\left(1-\frac{1}{\sigma \cdot m}\right)=w
$$

and given an inter-industry symmetric equilibrium prices are equal for all varieties, i.e., $p_{j}=P=1, \forall j=1, \ldots, n$. 


\subsection{Macroeconomic equilibrium}

The macroeconomic model is closed when: (i) aggregate output equals aggregate demand, i.e., $\sum_{j=1}^{n} p_{j} \cdot \sum_{i=(j-1) \cdot m+1}^{j . m} y_{i}=P . Y ;^{4}$ (ii) total profit income is given by $\Pi=\sum_{i=1}^{j . m} \pi_{i}$; and (iii) labour supply equals labour demand, i.e., $L=\sum_{i=1}^{j . m} L_{i}$.

\subsection{Entry}

Let us assume now firms are free to enter or leave the market in order to eliminate pure profits. Since profits depend on the level of aggregate demand (or output), there is a single value for $Y$ that generates $\pi_{i}=0$, given $m$ and $n$

$$
Y=(\sigma \cdot m-1) . \Phi \cdot n \cdot m
$$

Simultaneously, the macroeconomic equilibrium under a free-entry regime is given by the following condition

$$
Y=(1-\alpha) \cdot G+\alpha \cdot \frac{\sigma \cdot m-1}{\sigma \cdot m}
$$

Combining (7) and (8) we obtain a reduced form for the zero-profit condition, given by $h(n, m, G)=0$, where, using the implicit-function theorem, it is easy to see that

\footnotetext{
${ }^{4}$ In a model with differentiated products, (nominal) aggregate output is given by (nominal) value added created in all industries.
} 
$\partial h / \partial n<0, \partial h / \partial m<0,{ }^{5}$ and $\partial h / \partial G>0$. Thus, there are not enough equations to determine all the endogenous variables in the model. This indeterminacy is depicted in Figure 1. If we depart from point A, for $G_{1}>G_{0}$, entry can lead to a situation with more industries (point B), more firms per industry (point C), or a combination of both (somewhere on BC), all on the same isoprofit schedule ${ }^{6}$.

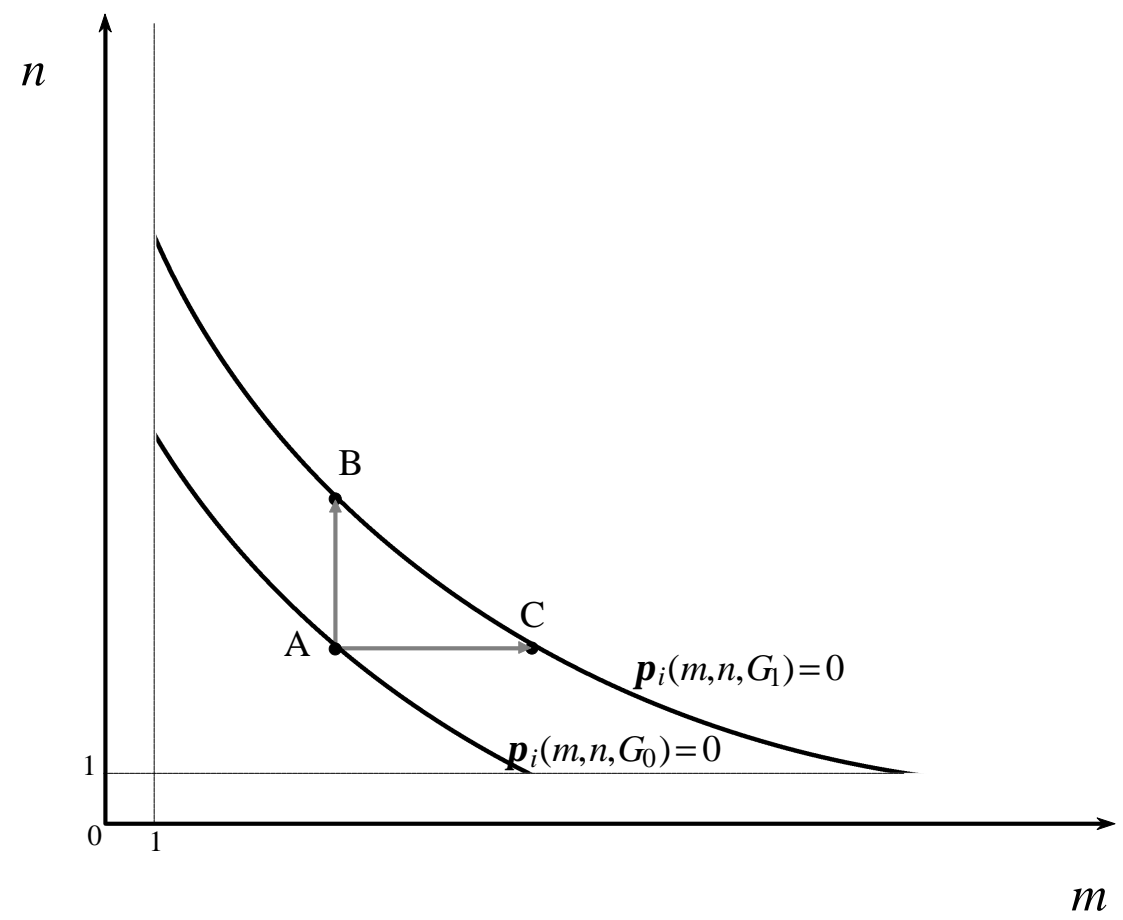

FIG. 1: THE ZERO-PROFIT CONDITION AND ENTRY

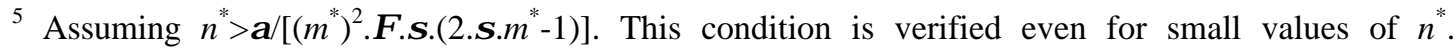
Imposing $G=0$ in the initial steady state, the condition is transformed into $n^{*}>\alpha . \sigma / \Phi$, and $\Phi<1$ in order to obtain $m^{*}=\sqrt{\alpha . \sigma \cdot n \cdot \Phi} /(\sigma \cdot n . \Phi) \geq 1$.

${ }^{6}$ I will treat $n$ and $m$ as continuous variables, despite the fact they are integers in reality. Of course this is only a simplifying assumption and one can interpret these numbers as averages.
} 
For sake of simplicity I analyse both extreme situations in alternative: in case I entry leads to more industries ( $n$ is endogenous) and the number of firms is always the same as in MC models; in case II entry leads to more firms per industry ( $m$ is endogenous) and the number of industries is fixed.

\section{The multiplier}

The free-entry multiplier, in this model, is given by

$$
\frac{d Y^{*}}{d G}=(1-\alpha)+\alpha \cdot \frac{d w^{*}}{d m^{*}} \cdot \frac{d m^{*}}{d G},
$$

where asterisks denote equilibrium values for the variables. Given equation (6), $d w^{*} / d m^{*}=1 /\left[\sigma .\left(m^{*}\right)^{2}\right]>0$, i.e., an exogenous increase in $m$ reduces the markup, expanding labour demand, and the real wage increases as a consequence. Furthermore, this effect decreases when more competition is introduced either at the intra-industry level (a larger value for $m$ ) or at the inter-industry level (a larger value for $\sigma$ ). In the Walrasian case (i.e., when $\sigma \rightarrow \infty$ and/or $\left.m^{*} \rightarrow \infty\right)^{7}, d w^{*} / d m^{*}=0$.

In case I ( $n$ is endogenous), $d m^{*} / d G=0$, i.e., the markup is fixed and so is the wage rate. Thus, fiscal policy stimulates output, but there is no difference between the CMC and the Walrasian multipliers, both given by $1-\alpha$. This is the main result in Startz (1989): once the profit mechanism is switched off, government expenditure partially crowds out private consumption in the same way, despite the markup level.

\footnotetext{
${ }^{7}$ Of course $\Phi=0$ in the Walrasian case, to rule out increasing returns.
} 
In case II ( $m$ is endogenous), it is easy to recognise fiscal policy induces more firms per industry

$$
\left.\frac{d m^{*}}{d G}\right|_{\text {Case II }}=\frac{(1-\alpha) \cdot \sigma \cdot\left(m^{*}\right)^{2}}{n^{*} \cdot \Phi \cdot \sigma \cdot\left(m^{*}\right)^{2} \cdot\left(2 \cdot \sigma \cdot m^{*}-1\right)-\alpha}>0 .
$$

Here, when government expenditure stimulates aggregate demand, profits increase and more firms enter existing industries. Consequently, intra-industry competition increases, the markup decreases, and extra wage income induces another round of the multiplier. Entry generates an aggregate demand externality, as it induces efficiency gains in the economy. It is easy to notice that $\alpha \cdot d w^{*} / d G$, the efficiency gain, is decreasing in both $\sigma$ and $m$. Thus, it is a decreasing function of the monopoly degree in the economy ${ }^{8}$. In this case, free entry does not eliminate the difference between the $\mathrm{CMC}$ and the Walrasian multiplier, and this difference is strictly increasing in the level of market power, as it happens in 'short-run' models.

\section{Steady-State Multipliers in an Intertemporal Extension}

In this section I extend the previous model to a dynamic setting. However, I will keep the basic DMS assumptions to eliminate other possible explanations for the differences between the fixed- and endogenous-markup multipliers.

Here, the household maximises an intertemporal utility function ${ }^{9}$ given by

\footnotetext{
${ }^{8}$ The Lerner index is given by $\mu=1 /\left(\sigma . m^{*}\right)$.

${ }^{9}$ Population is stationary and normalised to unity.
} 


$$
u=\int_{0}^{\infty} e^{-\rho . t} \cdot \frac{U^{1-\theta}-1}{1-\theta} \cdot d t,{ }^{10}
$$

where $0<\rho<1$ represents the discount factor and $\theta>0$ stands for the reciprocal of the intertemporal elasticity of substitution. This household can accumulate a stock of the aggregate consumption good and rent it under the form of capital $(K)$ to firms in a perfectly competitive market at price $R$. Thus, its budget constraint is given by

$$
\dot{K}=w \cdot L+R \cdot K+\Pi-C-T-\delta . K .^{11}
$$

Maximising the current-value Hamiltonian, we obtain the following behavioural equations from the first-order conditions

$$
\begin{aligned}
& \frac{\dot{C}}{C}=\frac{1}{\theta} \cdot\left[R-(\rho+\delta)-(1-\alpha) \cdot(1-\theta) \cdot \frac{\dot{w}}{w}\right], \\
& L=1-\frac{1-\alpha}{\alpha \cdot w} \cdot C,
\end{aligned}
$$

plus the transversality condition. Equation (13) represents the consumption Euler equation and equation (14) gives us the labour supply.

Firms use a Cobb-Douglas technology with an overhead

$$
y_{i}+\Phi=F\left(K_{i}, L_{i}\right) \equiv A \cdot K_{i}^{\beta} \cdot L_{i}^{1-\beta},
$$

\footnotetext{
${ }^{10}$ Time subscripts are ignored for simplicity.

${ }^{11}$ Again, the aggregate good is chosen to be the numéraire.
} 
where $0<\beta<1$ and $A>0 .{ }^{12}$ Considering firms do not accumulate capital, they face a static maximisation problem $^{13}$. Therefore, the Lerner index is also given by $\mu=1 /(\sigma . m)$. The first-order conditions can be written as

$$
\begin{aligned}
& \left(1-\mu_{i}\right) \cdot M P L\left(K_{i}, L_{i}\right)=\frac{w}{p_{j}}, \\
& \left(1-\mu_{i}\right) \cdot M P K\left(K_{i}, L_{i}\right)=\frac{R}{p_{j}},
\end{aligned}
$$

where $M P L$ and $M P K$ represent respectively the marginal products of labour and capital.

In a symmetric equilibrium the aggregate (gross) output is given by $Y=F(K, L)-n . \Phi$. Furthermore, considering $F($.$) is homogenous of degree one, we can use Euler's$ theorem to compute pure profits: $\Pi=\mu . F(K, L)-n . \Phi$. Thus, in a zero-profit situation at every moment in time, the aggregate production function can be written as $Y=(1-$ $\mu) . F(K, L)$, i.e., considering a fixed markup, this economy is equivalent to a Walrasian economy using a less efficient technology than $F($.$) .$

\footnotetext{
${ }^{12} \mathrm{I}$ assume there is no technical progress, although the model could easily be extended to include exogenous growth.

${ }^{13}$ If firms were to be the capital owners, open-loop strategies would generate the same outcomes. However, considering feedback strategies (sub-game perfect equilibrium) for an infinitely living firm induces strategic investment. In this type of environment it is not easy to find a closed-form solution outside the linear-quadratic framework. See inter alia Driskill and McCafferty (1989) or Fershtman and Kamien (1987).
} 


\subsection{The fixed markup model}

In the case of a fixed value of $m$ (e.g., equal to one), the markup level is fixed $(\mu=1 / \sigma)$. Let us define net output as gross output minus capital depreciation $Y_{n}=Y-\delta . K$. Using this definition in equation (13), steady-state consumption can be expressed as $C^{*}=Y_{n}^{*}-G^{*}$. Using equation (17), we can also express the steady-state capital stock as

$$
K^{*}=\frac{\beta}{\rho+(1-\beta) \cdot \delta} \cdot Y_{n}^{*}
$$

Now, equation (14) gives rise to:

$$
L^{*}=\frac{\mathrm{T}_{0} Y_{n}^{*}}{\left(1+\mathrm{T}_{0}\right) Y_{n}^{*}-G},
$$

where $T_{0}=(1-\beta) \cdot(\rho+\delta) \cdot \alpha /[(1-\alpha) \cdot(\rho+(1-\beta) \cdot \delta)]>0$. Considering the net output definition, its steady-state value is given by $Y_{n}^{*}=\mathrm{T}_{1} \cdot(1-\mu) \cdot F\left(K^{*}, L^{*}\right)$, where $\mathrm{T}_{1}=(1-\beta) \cdot \alpha /[(1-$ $\left.\alpha) \cdot T_{0}\right]>0$. Using both (18) and (19) in the production function, we obtain an expression for steady-state net output under free entry:

$$
Y_{n}^{*}=f(\mu)+(1-v) \cdot G, \quad f(\mu)=\Gamma_{0} \cdot(1-\mu)^{\frac{1}{1-\beta}},
$$

where $\Gamma_{0}=\mathrm{T}_{0} /\left(1+\mathrm{T}_{0}\right) \cdot\left(\mathrm{T}_{1} \cdot A\right)^{1 /(1-\beta)} \cdot\{\beta /[\rho+(1-\beta) \cdot \delta]\}^{\beta /(1-\beta)}>0$ and

$$
0<v \equiv \frac{\alpha \cdot(1-\beta) \cdot(\rho+\delta)}{(1-\beta) \cdot(\rho+\delta)+\beta \cdot \rho \cdot(1-\alpha)}<1 .{ }^{14}
$$

\footnotetext{
${ }^{14}$ This expression is equivalent to the static-model multiplier, as $v$ tends to $\alpha$ when $\beta$ or $\rho$ tend to zero.
} 
Again, the steady-state multiplier does not depend on the level of monopoly power, as in case I in the static model:

$$
\frac{\partial Y_{n}^{*}}{\partial G}=1-v
$$

Net output is increasing in the government consumption level and decreasing in the level of monopoly power.

\subsection{The endogenous markup model}

Here I assume, as in case II in the previous section, that firms are free to enter or leave any existing industry. Therefore, the markup level is now an endogenous variable, determined by the zero-profit condition, for a given $n$. Notice the Lerner index is given by $\mu^{*}=1 /\left(\sigma . m^{*}\right)$ :

$$
\mu^{*} \cdot F\left(K^{*}, L^{*}\right)=m^{*} \cdot n \cdot \Phi \Leftrightarrow \mu^{*}=g\left(Y_{n}^{*}\right)
$$

It is easy to observe the markup decreases with net output:

$$
\frac{\partial \mu^{*}}{\partial Y_{n}^{*}}=g^{\prime}\left(\mu^{*}\right)=-\frac{\left(\mu^{*}\right)^{3} \cdot\left(1-\mu^{*}\right)}{\sqrt{\mathrm{T}_{2}} \cdot\left[2+\frac{\mathrm{T}_{2}}{\sqrt{1-\mu^{*}}}\right]}<0,
$$

where $\mathrm{T}_{2}=\sqrt{n \cdot \Phi \cdot \mathrm{T}_{1} / \sigma}>0$. Since net output is a function of government consumption, ultimately the markup level is also determined by $G$. Thus, we can differentiate (20) and use the implicit function theorem to show that 


$$
\frac{d \mu^{*}}{d G}=\frac{g^{\prime}\left(\mu^{*}\right)}{1-g^{\prime}\left(\mu^{*}\right) \cdot f^{\prime}\left(\mu^{*}\right)} \quad, \quad f^{\prime}\left(\mu^{*}\right)=-\frac{\Gamma_{0} \cdot\left(1-\mu^{*}\right)^{\frac{\beta}{1-\beta}}}{1-\beta}<0
$$

When the mark-up level increases profits tend to be larger for the same value of $F($.$) , and this is a positive direct effect on profits. However, the steady-state values for$ both capital and labour tend to be smaller with more monopoly power, and this is an indirect effect on profits. For plausible values of the parameters one could expect the direct effect to be larger than the indirect. Assuming this is true, it implies that 1$g^{\prime} . f^{\prime}>0$ and consequently the markup decreases with government consumption.

However, considering an endogenous markup introduces further problems in the equilibrium definition. Galí (1994a) showed multiple equilibria can emerge in this type of models as $R=\left(1-\mu^{*}\right) \cdot M P K^{*}$ may not always be decreasing in $K^{*}$ : an increase in the capital stock decreases its marginal product, but it also decreases the markup, generating a positive effect on $R$. Considering $\partial R / \partial K^{*}=0$ is a non-linear equation in this model, multiple equilibria may exist here as well. However, there are also two constraints to be considered: (i) an equilibrium has to generate a capital stock level below the modified golden rule, and (ii) the equilibrium must be stable ${ }^{15}$ in order to apply the usual steady-state analysis. For simplicity, I will conduct my analysis ignoring this problem and I will propose a 'conservative' set of parameters to assess the values of the multipliers and the possibility of multiple equilibria arising with them.

\footnotetext{
${ }^{15}$ In Galí (1994a), the 'middle' equilibrium may either be a 'source' or a 'sink,' but the other two are always saddle-point stable.
} 
Therefore, for a (saddle-point stable) equilibrium, the multiplier is given by

$$
\frac{d Y_{n}^{*}}{d G}=(1-v)+f^{\prime}\left(\mu^{*}\right) \cdot \frac{d \mu^{*}}{d G}
$$

Again, an increase in government spending stimulates aggregate demand, inducing more firms to enter the existing industries. The markup level decreases and total factor productivity increases as a consequence. Notice both $d \mu^{*} / d G$ and $f^{\prime}\left(\mu^{*}\right)$ tend to zero when the Lerner index tends to zero. Also, consumption crowding-in cannot be ruled out. It can also be demonstrated that

$$
\begin{aligned}
& \frac{\partial\left[f^{\prime}\left(\mu^{*}\right) \cdot \frac{d \mu^{*}}{d G}\right]}{\partial \mu^{*}}=\frac{(1-\alpha) \cdot(1-\beta) \cdot[\rho+\delta \cdot(1-\beta)] \cdot n \cdot \Phi}{h^{2}} \cdot \Delta \\
& \Delta=2 .\left(1-\mu^{*}\right)^{2} \cdot[(1-\beta) \cdot \delta+\rho \cdot(1-\alpha \cdot \beta)] \cdot n \cdot \Phi- \\
& \quad-\left(\mu^{*}\right)^{2} \cdot \sigma \cdot G \cdot(1-\alpha) \cdot(\rho+\delta) \cdot\left[\left(\mu^{*}\right)^{2}+6 \cdot\left(1-\mu^{*}\right)\right]
\end{aligned}
$$

where $h$ is a very complicated function of the parameters. It is not easy to demonstrate this partial derivative is always positive as it depends on the sign of $\Delta$. However, numerical simulation showed that, for plausible levels of the markup measure, i.e., for $\mu^{*}<0.5^{(16)}$, the multiplier is an increasing function of the initial markup level.

Finally, I use a 'conservative' set of parameters to illustrate the quantitative differences that may be obtained between multipliers in case I (exogenous markup) and case II (endogenous markup) in this dynamic setting. Table I shows the parameter values used.

\footnotetext{
${ }^{16}$ That means marking the price less than $100 \%$ above the marginal cost.
} 
TABLE I

SteAdy-STATE MultiPliers

\begin{tabular}{cccccccc}
\hline \hline$A$ & $\alpha$ & $\beta$ & $\delta$ & $\rho$ & $\Phi$ & $n$ & $G$ \\
\hline 1 & 0.1816 & $1 / 3$ & 0.025 & 0.015 & 0.000029 & 1000 & 0.0878
\end{tabular}

The values for $\beta$ (equals the capital share in steady-state GDP), $\rho$ and $\delta$ are standard in the literature, $n$ was chosen to be a large number, $\alpha$ is consistent with $L^{*}=0.2, G$ generates a government consumption share in GDP equal to 0.2 , and $\Phi$ produces a $\mu^{*}=0.17$ (prices are marked $20 \%$ above the marginal cost). Only one equilibrium can be found for this parameter set ${ }^{17}$ and the multipliers are 0.843 in case I and 0.944 in case II, i.e., the endogenous markup multiplier is $12 \%$ larger than the fixed markup one.

This type of efficiency gains can also be found in Devereux et al. (1996). However, the transmission mechanism of fiscal policy does not depend on an endogenous markup, but in increasing returns to specialisation, i.e., entry (in a monopolistic competition framework) as a positive externality in a final-good sector with a production function that exhibits 'love for variety.'

One of the weaknesses of the approach presented here is that the type of entry is not endogenously determined in the model. However, this is also the case in a monopolistically competitive framework, where firms are barred from entering existing industries. Considering aggregate demand as a positive effect on intra-

\footnotetext{
${ }^{17}$ The equilibrium is saddle-point stable, as the eigenvalues are $\lambda_{1}=0.026$ and $\lambda_{2}=-0.074$.
} 
industry competition, there will always be some efficiency gains from increased competition.

\section{Conclusions}

The endogenous markup hypothesis has been ignored in traditional static general equilibrium models with imperfectly competitive goods markets. Considering the possibility of entry in existing industries produces efficiency gains enhancing the effectiveness of fiscal policy.

Even when entry eliminates profits, fiscal policy is shown to be more effective under Cournotian Monopolistic Competition than in the Walrasian case, when the number of firms per industry responds to the aggregate demand stimulus. More intraindustry competition leads to a smaller markup, larger real wages, and it launches another round of the multiplier.

This possibility is consistent with the evidence on counter-cyclical markups and points towards the necessity of studying the crossed effects between fiscal and industrial policies.

ISEG - Technical University of Lisbon, and UECE

\section{References}

d'Aspremont C., R. Santos Ferreira, and L.-A. Gérard-Varet: "General Equilibrium Concepts under Imperfect Competition: a Cournotian Approach," Journal of Economic Theory, 73 (1997), 199-230.

Devereux M., A. Head, and B. Lapham: "Monopolistic Competition, Increasing 
Returns, and the Effects of Government Spending," Journal of Money, Credit, and Banking, 28 (1996), 233-254.

Dixit A., and J. Stiglitz: "Monopolistic Competition and Optimum Product Diversity," American Economic Review, 67 (1977), 297-308.

Dixon H.: "A Simple Model of Imperfect Competition with Walrasian Features," Oxford Economic Papers, 39 (1987), 134-160.

Dixon H., and P. Lawler: "Imperfect Competition and the Fiscal Multiplier," Scandinavian Journal of Economics, 98 (1996), 219-231.

Driskill R., and S. McCafferty: "Dynamic Duopoly with Adjustment Costs: a differential game approach," Journal of Economic Theory, 49 (1989), 324-338.

Fershtman C., and M. Kamien: "Dynamic Duopolistic Competition with Sticky Prices," Econometrica, 55 (1987), 197-201.

Galí J.: "Monopolistic Competition, Business Cycles, and the Composition of Aggregate Demand," Journal of Economic Theory, 63 (1994 a), 73-96.

__ : "Monopolistic Competition, Endogenous Markups, and Growth," European Economic Review, 38 (1994b), 748-756.

_ _ "Product Diversity, Endogenous Markups, and Development Traps," Journal of Monetary Economics, 36 (1995), 39-63. 
Hart O.: "A Model of Imperfect Competition with Keynesian Features," Quarterly Journal of Economics, 97 (1982), 109-138.

Heijdra B., and F. van der Ploeg: "Keynesian Multipliers and the Cost of Public Funds under Monopolistic Competition," Economic Journal, 106 (1996), 1284-1296.

Mankiw N. G.: "Imperfect Competition and the Keynesian Cross," Economic Letters, 26 (1988), 7-14.

Martins, J. and S. Scarpetta: "The Levels and Cyclical Behaviour of Mark-ups Across Countries and Market Structures," OECD Economics Department Working Papers, 213 (1999).

Molana H., and C. Montagna: "Market Structure, Cost Asymmetries, and Fiscal Policy Effectiveness," Economics Letters, 68 (2000), 101-107.

Reinhorn L.: "Imperfect Competition, the Keynesian Cross, and optimal fiscal policy," Economics Letters, 58 (1998), 331-337.

Rotemberg J., and M. Woodford: "Markups and the Business Cycle," NBER Macroeconomics Annual, 6 (1991), 63-128.

__ : "Dynamic General Equilibrium Models with Imperfectly Competitive Product Markets," in Frontiers of Business Cycles Research, ed. by T. Cooley. Princeton: Princeton University Press, 1995. 
Startz R.: "Monopolistic Competition as a Foundation for Keynesian Macroeconomic Models," Quarterly Journal of Economics, 104 (1989), 695-713.

Torregrosa R.: "On the Monotonicity of Balanced Budget Multiplier under Imperfect Competition," Economics Letters, 59 (1998), 331-335.

Wu Y., and J. Zhang: "Endogenous Markups and the Effects of Income Taxation: Theory and evidence from OECD countries," Journal of Public Economics, 77 (2000), 383-406. 